\title{
AN EARLY OCULAR SIGN IN FACIAL PARESIS
}

BY

HeNRY Cohen, M.D.Liverp., F.R.C.P.Lond.

PROFESSOR OF MEDICINE, UNIVERSITY OF LIVERPOOL HONORARY PHYSICIAN, ROYAL INFIRMARY, LIVERPOOL

THERE are many named signs of paralysis of the facial nerve. These are, however, observed only when the facial weakness is of such degree that no special sign is necessary to demonstrate its existence. The following sign is present at an early stage, often before any demonstrable asymmetry of facial movement, and is late in disappearing when the nerve is recovering its function, e.g., in Bell's palsy.

Upward movement of the eye is naturally accompanied by contraction of four muscles:- superior rectus, inferior oblique, frontal belly of occipito-frontalis, and the levator palpebrae superioris, the latter ensuring uncovering of the eyeball during upward movement. If a normal individual be told to "look upwards but keep the eyes closed," the stronger contraction of the orbicularis palpebrarum, in keeping the eyelids together, masks the contraction of levator palpebrae superioris. If there be any weakness of the orbicularis palpebrarum, it can no longer antagonise the contraction of levator palpebrae superioris and the eye tends to open. This degree of weakness occurs in the early stages of facial paresis, and late in the recovery stage. In the more marked degrees of facial paralysis where the orbicularis palpebrarum is grossly affected, no closure of the eyes is possible and the facial paresis is evident.

\section{AN ADDITIONAL COMPONENT OF THE CONVERGENCE - ACCOMMODATION REFLEX}

\author{
BY
}

Henky Cohen, M.D.Liverp., F.R.C.P.Lond.

PROFESSOR OF MEDICINE, UNIVERSITY OF LIVERPOOL HONORARY PHYSICIAN, ROYAL INFIRMARY, LIVERPOOL

Hitherto, the convergence-accommodation reflex has been described as possessing two clinically observable components,

1. Convergence of the eyes, due to the action of the internal recti,

and 2. Contraction of the pupil.

Observation shows that a third component must be added, namely,

3. Relaxation of the levator palpebrae superioris with consequent lowering of the upper eyelid.

The loss of this third component of the reflex is one of the earliest ocular signs in chronic encephalitic Parkinsonism and hyperthyroidism. 